Article

\title{
Pursuing Inclusive Higher Education in Egypt and Beyond through the Convention on the Rights of Persons with Disabilities
}

\author{
Janet E. Lord * and Michael Ashley Stein \\ Harvard Law School Project on Disability, Harvard Law School, Cambridge, MA 02138, USA; E-Mails: lord@american.edu \\ (J.E.L.), mastein@law.harvard.edu (M.A.S.) \\ * Corresponding author
}

Submitted: 2 August 2018 | Accepted: 15 October 2018 | Published: 6 December 2018

\begin{abstract}
Inclusive higher education is elusive for students with disabilities, especially in developing countries. The adoption and rapid ratification of the Convention on the Rights of Persons with Disabilities (CRPD) provides, if applied as its drafters intended, a "whole of institution" framework for its realization (CRPD Committee, 2016). Myriad legal, attitudinal, physical, and communication-based barriers limit or exclude participation. The individual impact of such discrimination is clear and carries lifelong consequences. Equally endemic are the broad societal and pedagogical effects of this exclusion. To illustrate: preventing persons with disabilities from Teacher Education courses impacts inclusive education in primary and secondary education; barring people with disabilities from academic programs in the sciences stifles innovation in assistive technology, health, and rehabilitation; and limiting access to studying the humanities hampers the emergence of disability studies as a rightful discipline. This article presents a framework for inclusive higher education in developing countries as contemplated by the CRPD. In doing so, we draw on field work conducting the first assessment of the accessibility of Egyptian public higher education to students with disabilities. We outline lessons that can be learned and pitfalls to be avoided both in Egypt and indeed for other countries in the Global South.
\end{abstract}

\section{Keywords}

accessibility; Convention on the Rights of Persons with Disabilities; disability rights; Egypt; Global South; higher education; human rights; inclusive education; international development; students

Issue

This article is part of the issue "Students with Disabilities in Higher Education", edited by Geert Van Hove (Ghent University, Belgium/VU Amsterdam, The Netherlands), Minne Bakker (VU Amsterdam, The Netherlands) and Alice Schippers (Disability Studies in the Netherlands/VU Amsterdam, The Netherlands).

(C) 2018 by the authors; licensee Cogitatio (Lisbon, Portugal). This article is licensed under a Creative Commons Attribution 4.0 International License (CC BY).

\section{Introduction}

Globally, students with disabilities face historic and deeply entrenched barriers relative to their non-disabled peers in accessing higher education at the university, graduate, or post-graduate level (Harpur \& Stein, in press-a). This is particularly true in the context of the developing world where the exclusion of these students is predicated on several factors including stigma, prior exclusion from primary and secondary education, social isolation, and resource constraints (Harpur \& Stein, in press-b). Ironically and deleteriously, precluding students with disabilities from advanced education dramatically increases their likelihood for experiencing poverty and their exclusion thus adds to the vast challenges experienced by persons with disabilities and their communities in the Global South (Heymann, Stein, \& Moreno, 2014; Trani, Kett, Bakhshi, \& Bailey, 2011).

The right of persons with disabilities to equally access higher education was implied by Article 23(3) of the United Nations Convention on the Rights of the Child (CRC), and subsequently affirmed in non-binding instru- 
ments (CRC, 1989; Standard Rules, 1993; UNESCO, 1994). The right to inclusive education was established unambiguously by Article 24 of the United Nations Convention on the Rights of Persons with Disabilities (CRPD) through its mandate for "an inclusive education system at all levels and lifelong learning" (CRPD, 2006) as an integral component of realizing other disability-related human rights. Article 24 accordingly prohibits disability discrimination at all levels and requires that reasonable accommodations be provided to facilitate full inclusion and quality education (CRPD, 2006). The framework sets out, for the first time in a legally binding instrument, a "whole of institution" approach to inclusive education for all levels of education (Ainscow \& Florek, 1989; CRPD Committee, 2016). In doing so, it promotes a standpoint theory that privileges the voice, experience, and knowledge of persons with disabilities over all others while avoiding "the categorical authority" that seeks to sideline precisely the experience of others whose social and contextual standpoint as non-disabled are integral to addressing barriers (Shildrick, 2012, pp. 36-37). The provisions of the treaty, at various points across the text, call out for critical engagement with the discourses of exclusion, whether in education or any other realm.

The barrier-dismantling directive of the CRPD, accordingly, is to assess the entirety of the educational experience and environment in identifying and removing barriers for students with disabilities. The Committee on the Rights of Persons with Disabilities (CRPD Committee)-the treaty body tasked with interpreting, monitoring, and enforcing the CRPD-addressed accessibility within education in its General Comment No. 2. There it affirmed that "it is the entire process of inclusive education that must be accessible, not just buildings, but all information and communication, including ambient or FM assistive systems, support services and reasonable accommodation in schools" (CRPD Committee, 2014).

Accessibility as it is understood in Article 9 of the CRPD further reflects the notion that persons with different disabilities may require distinctive strategies and supports to enjoy equal opportunity via services offered by higher education institutions. These standards form the basis for assessing compliance with human rightsbased inclusive education mandates. They are fleshed out in the CRPD Committee's General Comment No. 4 on inclusive education (CRPD Committee, 2016). Arising from Article 24 and General Comment No. 4 is the notion of "quality inclusive education", comprising those elements of education aligned with the CRPD's international human rights law framework. These include availability, accessibility (including non-discriminatory access and the provision of reasonable disability-related accommodations), acceptability, and adaptability, with the aim of full participation and inclusion, on an equal basis with others (CRPD, 2006, arts. 3, 5, 24, 30; CRPD Committee, 2016; de Beco, 2016).

Guidance contained in General Comment No. 2 and General Comment No. 4, underscore that Article 24 en- sures equal access to students with disabilities in higher education even as its practical manifestations remain a work in progress. Indeed, most States ranging from Australia to the United States, and Uganda to South Africa, struggle to provide equal access for students with disabilities to State-based higher education (Foundation of Tertiary Institutions of the Northern Metropolis, 2011; Harpur \& Stein, in press-a; Linder, Fontaine-Rainen, \& Behling, 2015). Consequently, many obstacles remain to achieving the legally and socially required goal of inclusive higher education.

Yet, notwithstanding these barriers, significant factors raise hopeful prospects for global improvement. Persons with disabilities are now explicitly recognized as development stakeholders in international development programs and policies, including the nearlyuniversally ratified CRPD, the Sustainable Development Goals (SDGs), and the embrace of disability-inclusive development by bilateral and multilateral donors (CRPD, 2006, art. 32; UN Development Programme, 2016; World Bank Group, 2007). Hence, global drivers towards inclusive development may open up inclusive higher education for students with disabilities. Certainly, this promising and worldwide shift towards inclusivity in higher education policy has translated nationally in Egypt with the emergence of the 2014 Constitution, the 2030 Sustainable Development Strategy (SDS), and the 2018 Egyptian Disability Law. To illustrate: the eleven references to disability within the SDGs, which include the right to equally access higher education, were responded to by Egypt's SDS which confirmed these rights and introduced some inclusive measures.

This article draws on field work undertaken in 2017 on behalf of the US Agency of International Development (USAID) assessing multiple barriers faced by students with disabilities when accessing Egyptian universities and technical colleges. Following a review of our research methodology, Section 3 provides an overview of the legal and data barriers to inclusive higher education in Egypt. Next, Section 4 sets forth the bulk of our findings relating to educational hindrances to inclusive higher education in Egypt. Seeking to ameliorate such obstacles, Section 5 recommends steps to accelerate CRPD implementation as a means of promoting inclusive higher education in Egypt, as well as other Global South countries. Throughout, we maintain that the CRPD framework, when properly applied in its entirety and complexity, offers a legal template for advancing an inclusive "whole of institution" approach to inclusive higher education.

\section{Research Methodology}

The research project into the accessibility of students with disabilities to higher education in Egypt assessed, among other things, the needs of students currently enrolled in Egyptian public universities and technical colleges (collectively, public higher education institutions, 
or HEIs) and the barriers they experienced. We examined twenty-four public universities and eight technical colleges across Egypt (Lord, 2017) and utilized a mixed methods approach. Nineteen data collection tools were developed for the field work and included nine key informant interview protocols, three group discussion protocols, two paper and pencil surveys, two online surveys, a facility accessibility tool, and an online accessibility checklist for manual and automated audits. Components of the field work included key informant interviews (KIIs) with Egyptian governmental offices, donors, businesses, and site visits to HEls. At each university site, KIls were combined with the administration of structured survey instruments allowing students with disabilities, faculty, and staff to share their experiences via group discussions. during field visits. We also performed two accessibility audits, one of the built-environment at each $\mathrm{HEI}$ and another of the online environment. Ultimately, we reached a total of 825 stakeholders. Additionally, a desk review examined available data on the number of students with disabilities enrolled in HEls.

Finally, and marking the first of its kind in a disabilityinclusive development assessment of higher education, the tools were developed and mapped out against the CRPD. This was made possible by conducting a detailed legal analysis focused on assessing Egyptian commitments made in view of its CRPD ratification and probing deeply into the domestic indices of CRPD implementation which, like most domestic disability law frameworks, present not a single entry-point for analysis but rather a fragmented and often conflicting repository of legal provisions. Further, an accessibility audit was conducted of the physical environment of each $\mathrm{HEl}$, utilizing a modified version of a protocol used to assess compliance with building standards under the Americans with Disabilities Act, the accessibility standards on which the Egyptian building code is based. An automated and manual online web accessibility audit was performed for those HEls with an online presence. A major limitation of the research was that the assessment covered students with physical and sensory disabilities and not, overtly, students with learning, intellectual, or psychosocial disabilities. Currently, only students with physical and sensory disabilities are captured in existing data, and thus remain the focus of action by the Egyptian government in education. The resulting documentation detailing the assessment findings, conclusions and recommendations were set out in a comprehensive report and executive summary (Arabic and English) and also included accessible formats including an executive summary in Braille, and video in American Sign Language and Egyptian Sign Language (USAID, 2017).

\section{Part I: Legal and Data Barriers}

Beyond the purview of Egypt's higher education system, but nonetheless impacting directly upon its HEls, the study revealed multiple legal as well as data barriers to inclusive education for Egyptian students with disabilities. Mapping the findings against the CRPD framework reveals gaps as well as entry points for advancing accessibility in $\mathrm{HEI}$.

\subsection{Legal Barriers}

Egypt ratified the CRPD in 2008 and yet work underway to bring domestic legislation into alignment with the treaty were much delayed on account of political turmoil. The 2014 Egyptian Constitution does address the rights of persons with disabilities in nine specific provisions, providing a strong foundation for advancing disability rights, yet missing some helpful elements such as the requirement that reasonable accommodation be provided as a measure of meeting non-discrimination obligations (Constitution of Egypt, 2014). Still, the Constitution contains an explicit prohibition against disability-based discrimination and recognizes health, economic, social, cultural, entertainment, sporting, and education rights. Following the period of political turmoil, disability-specific legislation was adopted in 2018 and still requires detailed regulations to effectuate its provisions (Persons with Disabilities Act, 2018). Hence, there is ample opportunity to provide needed guidance for advancing the rights of persons with disabilities at all levels of education.

The 2013 Marrakesh Treaty to Facilitate Access to Published Works for Persons Who Are Blind, Visually Impaired, or Otherwise Print Disabled is not yet ratified, such that Egyptian law does not require book publishers to provide accessible formats of books-including, notably, textbooks for students at HEls (Marrakesh Treaty, 2013). A further problem which ratification and implementation of the Marrakesh Treaty would resolve is the practice of university professors creating their own materials and then refusing to share electronic copies on the basis of proprietary interest. Moreover, the absence of public procurement policies on ICT accessibility remains a significant gap in the legal framework. Although presently lacunae, each of these shortfalls likewise offers a promising avenue for change.

A greater shortcoming in the legal framework is the lack of a clearly prescribed and resource-supported legislative path from secondary school into higher education for students with disabilities. While this is suggested by the CRPD, it is a missing element in the Egyptian legal framework. Significantly, transition services to facilitate the move from secondary education to higher education are absent (Lord, 2017, pp. 10-11). Hence, students with disabilities are left without access to information on accessibility in HEls or the skills required to self-advocate for needed accommodations.

Moreover, few university-wide policies exist for students with disabilities across Egyptian HEls. This, too, is an element of CRPD implementation, via Article 4, yet largely missing from Egyptian HEI practice (CRPD, 2006, art. 4). Likewise, literature on advancing inclusive HEI is strongly suggestive of the need for clear and coher- 
ent policies for disability-inclusion (Emong, 2014; Reiser, 2012). Instead, the norm is ad hoc decision-making controlling the inclusion of students with various disabilities within specific HEls and their individual faculties and departments, creating major (and inconsistent) barriers for these students to access programs of their choosing. The few efforts that have been made to address HEls collectively have failed for lack of guidance or implementation (Lord, 2017, p. 15). While the Supreme Council of Universities (SCU) issued a decree allowing qualified students with disabilities to seek to enrol in any faculty they choose (SCU Decree, 2016), enrolment, however, remains subject to additional interviewing by individual faculty departments, with the possibility of appeal to the SCU where not approved. Further, the decree was not accompanied by guidelines on what support (including reasonable accommodations) students with disabilities should benefit from within HEls. Thus, it is unclear if the SCU decree will impact access and improve selection and choice. The study also disclosed that when reasonable accommodations and other supports are provided, it is also highly discretionary within HEls and often viewed as a gesture of good will rather than as a fulfilment of a duty (Lord, 2017, pp. 19-20).

\subsection{Disability Data Collection Gaps}

Literature abounds with evidence disclosing the lack of data and statistics on disability in education at any level, and where data exists it is unreliable (World Health Organization [WHO] \& World Bank Group, 2011). In 2003, the $\operatorname{OECD}(2003$, p. 23$)$ reported on the global dearth of reliable data on students with disabilities and their higher education outcomes. Yet even following near-universal CRPD ratification, only a few institutions anywhere require such data collection; strikingly, few national-level requirements exist for data collection on students with disabilities at any level of education (OECD, 2003).

Estimates put forward by the Central Agency for Public Mobilization and Statistics in Egypt indicates that $10.7 \%$ of the population is disabled, or nearly 11 million persons (CAPMAS, 2017) This does not strongly contradict the estimated global disability prevalence of $15 \%$ provided in the 2011 World Report on Disability (WHO \& World Bank Group, 2011). Disaggregated Egyptian data as to disability type is nevertheless hard to come by; a WHO household survey estimated $6 \%$ hearing loss, or some three million Egyptians (UNESCWA, 2015; WHO, 2015 , p. 19). The WHO also estimated that there are one million blind Egyptians (WHO, 2015, p. 19).

Our research revealed, unsurprisingly, that the actual number of students with disabilities in HEls is unknown (Lord, 2017, pp. 8-9). Those HEls with data readily acknowledged the numbers were unreliable because students with disabilities were significantly underreported. The largest university in Egypt, for instance, has some 270,000 students and yet acknowledged that they were able to account for under 1,000 students with disabilities; those who could be counted were identified because they had specifically sought out assistance from disability support services (Lord, 2017). Students with disabilities, faculty, and administrators further explained that student non-disclosure of disability is due to stigma, fear of discrimination, and concurrent restrictions on choice of studies.

\section{Part II: Educational Barriers}

Two conceptual notions reflected in the CRPD are upheld in the educational barriers disclosed in the data. First, the barriers identified are evident in legal, policy, physical and online environments, and in information, communication, and attitudes (CRPD, 2006, preamble (e), art. 1). This is not surprising, but the point should not be missed that the CRPD's conceptual framework responds to all dimensions of the social environment. Second, these realms of disadvantage are interdependent, interrelated, and indivisible in the manner that a rightsinformed frame makes clear (CRPD, 2006, preamble).

The following themes emerged from an analysis of our data: (1) pre-higher education barriers; (2) admission, enrolment, and program choice barriers; (3) attitudinal barriers; (4) physical environment and transport barriers; (5) course curricula and material barriers; (6) examination barriers; and (7) online environment barriers.

These barriers map out against the provisions of the CRPD; yet understanding these barriers and then pegging them to the CRPD provisions presents a common framework that moves beyond the "wouldn't it be nice" motivating factor into the more prescriptive law and policy realm. The discussions following in this and the subsequent section explain how this mandate may be implemented.

\subsection{Pre-Higher Education Barriers}

While the research focused primarily on the experience of students with disabilities currently enrolled in Egyptian HEls, a recurrent theme across interviews with students was that pre-higher education barriers ultimately impacted their experience in $\mathrm{HEI}$ and, in many respects, set students with disabilities up for failure. First, students pointed out the problem of documentation on secondary school records that disclosed attendance in an "inclusive education" environment. This notation flagged disability status and resulted in limiting choice of studies in HEls insofar as students were "outed" and thus marked for exclusion or restrictions by HEls. Second, students noted the lack of information about the availability of support services in HEls. Third, the students' self-advocacy skills were often weak, thus compromising the navigation of barriers and assertion of accommodation needs. Additional barriers included shortcomings in their computer and technological skills, including assistive technology usage, and restrictions on access to taking certain courses that, in turn, impacted choices within HEI (Lord, 2017). 
Differentiating among disability types, barriers experienced by students worked to disadvantage in various ways. Students identifying as blind emphasized limited opportunities for training at primary and secondary levels in the use of Braille and various assistive technologies needed to succeed at HEls, thus emphasizing ongoing issues in accessing knowledge content. Deaf students indicated that there was limited access to quality education and restricted or no access to accommodations (e.g., Egyptian Sign Language) which hindered their ability to acquire needed reading and writing skills (Lord, 2017, pp. 19-20). Finally, students with physical disabilities noted physical and built environmental barriers such as reduced access to transportation to schools, classrooms on a higher floor without elevator access, and inaccessible bathrooms (Lord, 2017, pp. 17-18). The upshot of these findings was that students with physical disabilities stayed at home altogether or simply missed out on certain lectures and activities. These findings dovetail with research into the specific barriers experienced by children with disabilities at primary and secondary levels of education in developing countries (Danso, Owusu-Ansah, \& Alorwu, 2012; Leonard Cheshire Disability, 2017).

The importance of the findings regarding experience prior to entry into university is that barriers existing in primary and secondary education may often have a knockon effect at higher levels, diminishing opportunity and access. The foregoing also connects to the obligation in the CRPD that requires due attention to accessibility at all levels of education (CRPD, 2006, art. 24). Likewise, the CRPD recognizes that self-advocacy and awareness measures for teacher and administrators is one among many skill sets needed and required to address entrenched stigma and discrimination (CRPD, 2006, art. 8).

\subsection{Admission, Enrolment, and Program Choice Barriers}

Our assessment revealed significant barriers in $\mathrm{HEI}$ admission, enrolment, and program choices, and additional obstacles even after admission by individual departments within HEI faculties. To begin with, admission criteria for students with disabilities into HEls are unclear or arbitrarily applied at the level of the faculty or individual department within a faculty (Lord, 2017, pp. 11-12). A typical reflection of this arbitrariness is the experience of a philosophy student with a physical disability: "The Faculty determines that we only join certain departments-they push us to join certain departments so not all are open to me" (Lord, 2017, p. 13). Likewise, another student explained: "I wished to study pharmacy, but they told me that they won't accept me in the major. I was persuaded to change to diploma instead....I'm not allowed because of my physical disability" (Lord, 2017). Students with physical disabilities also face restrictions in joining their department of choice. For example, students with upper arm amputation were not allowed to enrol in faculties that require extensive writing or drawing, regardless of their qualifications. Similarly, students with physical disabilities were more often than not denied entry into any medical field (Lord, 2017).

Notably, deaf students experienced the greatest barriers to admission in HEls. Even the recent SCU decree allowing students who are deaf permission to enrol into $\mathrm{HEI}$ faculties limits their enrolment to teacher training in the fields of music, arts education, home economics, and technology education (Lord, 2017). Likewise, students with visual impairments face severe restrictions in accessing their selected fields of study on account of both formal and informal exclusions (Lord, 2017, pp. 8-9). As one student noted: "After I became blind, while enrolled in the Faculty of Commerce, I was told I would need to switch faculties, which I did not want to do, so I left university" (Lord, 2017, p. 12). And some HEls had put into place written policies excluding blind students from enrolling in certain faculties. For example, at one HEI, although the Faculty of Education supported admitting students with disabilities, a university-wide bylaw on admissions did not (Lord, 2017, pp. 15-16). At another HEI, blind students could not enrol in the computer information faculty, even though, paradoxically, that same faculty housed an assistive technology centre for persons with disabilities.

All too often, even in the absence of written policies, it was found that informal practices and "general understandings" worked to disadvantage students with disabilities. Thus, at one university, two students with visual impairment were admitted to the sociology department only to be told a few days before the exam that they were being transferred to another department (Lord, 2017, pp. 11-12). Subtle pressure was applied, sometimes by a single faculty member, to dissuade a student from pursing a course of study and solely on the basis of disability, irrespective of qualification. Another student who acquired a visual impairment during his course of study was thus told he would no longer be able to pursue his studies in commerce and would need to transfer to the arts faculty; he dropped out of university as a result (Lord, 2017, pp. 11-12). This arbitrariness in decision-making is precisely what the CRPD attempts to address in requiring States to create a legislative and-especially for higher education institutions that operate more autonomously than lower levels of education-regulative basis for nondiscrimination (CRPD, 2006, art. 4).

\subsection{Attitudinal Barriers}

At eighteen of the twenty eight HEls visited, attitudinal barriers were apparent among faculty and staff, nondisabled students, and students with disabilities themselves. These perceptions about disability were regarded as a major barrier to full participation and inclusion in HEIs (Lord, 2017, pp. 13-14). At the same time, upper level HEI management (i.e., university presidents, vice presidents, and deans) conveyed high levels of interest in supporting students with disabilities. A major theme of all focus group discussions held with students with 
disabilities was the understanding ascribed to disability within $\mathrm{HEI}$ culture. While both the social and individ$\mathrm{ual} /$ medical models were apparent, the latter was the predominant model among faculty, staff, and administrators (Lord, 2017).

Not surprisingly, the findings on disability awareness barriers lead to the conclusion that faculty are unfamiliar with the rights of students with disabilities, including their right to access HEls on an equal basis with other students. Moreover, the failure to accommodate students with disabilities has a knock-on effect in terms of including faculty with disabilities in higher education which is shown to have a demonstrable (positive) impact on student attitudes about disability (Reiko \& May, 2011). Creating a more enabling environment within which greater knowledge and understanding of how to identify and remove barriers must take place concurrently with specific provision for training and education on disability exclusion, consistent with articles 8 (awareness-raising) and 9 (accessibility) of the CRPD.

\subsection{Physical Environment and Transport Barriers}

Following the CRPD framework for environmental accessibility, the study assessed physical access prior to reaching an HEl campus, entry and egress onto the campus facilities, movement around the campus, and accessibility features inside facilities (CRPD, 2006, art. 9).

Barriers in physical infrastructure and transport were evident across all HEls (Lord, 2017, pp. 17-18). Adopting the holistic approach required by the CRPD in Article 9, the assessment examined whether and how students with disabilities were reaching and benefitting from the all of the services offered, including lectures, library facilities, housing, sport and recreational events, and pathways across campus. Somewhat surprising given the low cost of basic barrier removal, physical barriers routinely prevented students with physical disabilities-especially wheelchair users, but also blind persons-from attending lectures and activities. Students, especially blind and physically disabled students, described the impact of multiple barriers in how such barriers impacted their getting to campus in the first place, and then restricted campus building entry and egress, and limited participation in field trips, extra-curricular activities and access to housing structures. Further, the results of accessibility audits uncovered barriers to water and sanitation facilities and inaccessible toilets in all campuses assessed. Somewhat disingenuously, resource limitations were cited as a major obstacle to ensuring physical access, especially to old buildings, by administrators, faculty, and engineering staff; old buildings in eighteen of the twenty eight HEls visited were not physically accessible. Nonetheless, the appearance of a disabled parliamentarian at one university's concert hall resulted in the construction of a wooden ramp within thirty minutes.

Only eleven of the twenty eight institutions visited had accessibility plans and measures to monitor and eval- uate accessibility of any kind and none that were effectively implemented to any significant degree (Lord, 2017, p. 18). Students were wholly reliant on the goodwill of other students or family members to mediate physical barriers inside and outside of campus buildings. Other hazards observed and reported by students included door thresholds; unlevelled, unpaved and rough walkways and roads around campus; and lack of safety railings in toilets or hallways. These physical barriers were found to limit students with disabilities' regular attendance at lectures and, inter alia, their access to education (Lord, 2017). Curiously, universities were not utilizing low cost solutions to address priority barrier removal, although a pilot program to assess and remove physical barriers in cooperation with a non-governmental organization at Cairo University offered some promise. Additional missed opportunities abounded for integrating barrier removal into academic programming, for instance by engaging with engineering faculties to provide students with campus-based academic and service learning opportunities. Finally, and underscoring the problems that arise when students with disabilities themselves are not consulted about resource allocation in barrier removal, 100 wheelchairs donated by a wealthy patron had no apparent distribution plan attached to it nor a needs assessment, and golf carts purchased for disabled students were ill-equipped for many and ill-coronated to facilitate timely transfers. Consultation as a precondition to decision-making, as required in Article 4(3) of the CRPD, assumes particular significance in a context where resources are limited and must be put to best use.

\subsection{Course Material and Curricula Barriers}

Difficulties in access course material and curricula were widely cited. A majority of students with visual impairment $(72 \%)$ and hearing impairment $(56 \%)$ reported barriers in obtaining course materials in an accessible format (Lord, 2017, pp. 19-20). As one blind student explained: "I have a printing problem there are legal issues related to copyright and it makes it hard to get what I need printed in Braille" (Lord, 2017, p. 20). A large minority of students with physical disabilities (44\%) faced similar problems (ibid). In addition, HEls are not facilitating the learning of Egyptian Sign language (ESL) or ensuring delivery of education in the most appropriate means for deaf students (CRPD, 2006, arts. 24, 30).

The results of the study disclosed that providing alternative formats (courses, exams) and accessible teaching modalities for the visually disabled (e.g., PDFs and PPTs) is all but unknown. Further, students and assistive technology staff explained that accessibility was seen as a measure of "good will" and not of "rights" (Lord, 2017, pp. 19-20). Hence, access to course materials in accessible formats is frequently dependent on the individual discretion of faculty members. Students, assistive technology staff, and library personnel similarly report delays in obtaining accessible formats of academic material (e.g., 
Braille, large print, audio recordings) due to resource constraints (Lord, 2017). In addition, assistive technology and library personnel report shortage of staffing, assistive technology, and technical know-how on up-to-date print access accommodations (e.g., Arabic language software). Unfortunately, in the absence of knowledge and understanding about the duty of HEls to provide reasonable accommodations to facilitate access to course material and curricula, students engaged in surreptitious selfhelp strategies, as in secretly recording lectures on their cell phone to listen to later on (Lord, 2017).

\subsection{Examination Barriers}

Barriers to accessing needed accommodations during examinations and assessments were a major issue noted by many students. Student surveys revealed that $94 \%$ of deaf students reported barriers in taking course examinations (Lord, 2017). Students with visual and physical disabilities pointed to the problem of poorly qualified readers and writers assigned to them during the examination period. They also noted the faculty perception that providing them with qualified readers/writers would give them an unfair advantage or pave the way for cheating (Lord, 2017). This points to the need for educating teachers and administrators about reasonable accommodations in the specific context of assessment and, in addition, to the need for university-wide regulation and quality control.

Beyond putting in place uniform policies and procedures, in some instances HEls had discriminatory processes in place according to which bylaws required readers and writers for students with disabilities to be younger and less qualified than the students they were assisting, apparently on the basis that this would prevent any unfair advantage. Students emphasized the need for by-laws that facilitated their access through qualified assistance. Many put forward their own solutions, pointing to the availability of computer technology that might allow students to have access to computer examinations to facilitate their access (Lord, 2017). Examples of desired accommodations noted by students with disabilities to achieve equal access to exams were diverse, and yet HEls were seemingly unaware that a core element of the duty to provide reasonable accommodations in education is individualizing such accommodations (CRPD, 2006, art. 2). The measure of reasonableness allows for the circumstance that not all types of accommodations will be possible (e.g., on account of the need for resources to obtain, for instance, the latest screen reading software), yet many exist that are readily achievable.

\subsection{Online Environment Barriers}

Online accessibility is an increasingly important dimension of higher education. Accordingly, barriers were assessed in the online environment against globally accepted standards for web content accessibility, namely, the Web Content Accessibility Guidelines, version 2.0. Webpages were tested against twelve guidelines organized under four key principles: perceivable, operable, understandable, and robust. Stark results were revealed: every $\mathrm{HEI}$ website viewed showed significant degrees of inaccessibility (Lord, 2017, pp. 22-23). Manual checks were undertaken to confirm automated barriers and to assess barriers that cannot be captured by automation. For instance, websites were inaccessible for students with visual impairment, utilizing assistive technologies (e.g., JAWS, NVDA, and VoiceOver), preventing easy page navigation or quickly accessing the entirety of the website. The near total absence of captioning on videos made such content inaccessible to persons with hearing impairment. Page navigation across the entirety of the HEI websites would be difficult for persons with physical disabilities where mouse navigation is not an option. Further, the existing Egyptian law and policy framework was silent on the accessibility of web content, online learning, or other increasingly important modes of access to materials (Lord, 2017).

Finally, interviews with students and faculty members with disabilities disclosed other barriers such as inaccessible content on Facebook pages, a highly utilized medium within HEls (and the primary online presence for seven of eight technical colleges), including no captioning on videos, no audio description for images, graphics. One faculty member noted the practice of informing faculty and staff across the university of upcoming events and meetings via PDF versions of xeroxed pages that were totally inaccessible even to his own screen reading technology (Lord, 2017). The Supreme Council on Higher Education conceded its lack of technical capability in making the growing online e-platform accessible but evidenced a strong interest in receiving such support. More than other areas of CRPD implementation, accessibility in the online environment was little understood notwithstanding explicit provision made for it in the treaty (CRPD, 2006, art. 9). The failure of HEls to facilitate the entry of blind and Deaf students into information technology and computer science programs demonstrates the potentially far-reaching consequences of limiting program choice. It stands to reason that such restrictions will stifle innovation (Haddon et al., 2005; Miller, Paul, Parker, \& Gillinson, 2004; Von Hippel, 2005).

\section{Part III: Recommendations to Advance Inclusive Higher Education}

It is one thing to catalogue obstacles to inclusion as the findings and conclusions of the USAID study highlight in comprehensive measure. It is quite another to tackle and dismantle these barriers, knowing in particular that local shortcomings align generally with findings in other developing countries where resource constraints create similar barriers for many, if not all students irrespective of disadvantage rooted in disability (Emong, 2014; Reiser, 2012). 
The radical claim of the CRPD is that such hindrances are not inevitably determined on account of the absence of material capabilities to dismantle them. Granted, in some instances, resources will impose a certain temporality, a limitation on how quickly some barriers must be removed (CRPD, 2006, art. 4). And these elements are embedded in the human rights framework that renders social rights-including education-subject to progressive achievement, and indeed, the reasonable accommodation duty which sets up some parameters (reasonableness, undue hardship) for the imposition of that duty (CRPD, 2006, arts. 2, 5). But a whole of institution approach, as laid out in the legal framework of the CRPD, makes many components of barrier-removal immediately realizable. In fact, the claim of the CRPD is that there are numerous grounds for advancement and these hinge on recognition of the legal capacity and personhood of persons with disabilities. Further, that progress can be best achieved by engaging persons with disabilities in the processes of barrier identification and removal. Thus, CRPD Article 4(3) astutely requires that persons with disabilities must be active agents in assessing all policies, laws, and programs. Real inputs from stakeholders would expose the absurdity-beyond its inherent illegality-of pushing people into certain schools and careers based on disability-type.

Moreover, a close reading of the CRPD, combined with a "whole of institution approach" to accessibility in higher education, offers guidance on the interventions required to advance accessibility for students with disabilities into quality higher education both in Egypt and beyond Lord (CRPD Committee, 2016, para. 12). Within HEIs, six core priority interventions are needed to advance inclusive quality higher education in Egypt. These include: (1) dismantling barriers in pre-higher education; (2) addressing law/policy and data gaps; (3) tackling disability stigma; (4) advancing inclusive curricula, materials, and examinations; (5) creating barrier-free infrastructure; and (6) ensuring ICT accessibility. We underscore the iterative and interrelated nature of these recommendations. At the same time, we acknowledge that bringing about the change contemplated by the CRPD will be constrained by availability of resources that constrict inclusion for all students in developing country high education, disabled and non-disabled alike. Yet in all of the areas requiring measures to advance inclusion and accessibility, a pre-condition to the expenditure of resources in a sensible direction is the meaningful participation by persons with disabilities to prioritize and generate solutions.

\subsection{Dismantling Barriers in Pre-Higher Education}

Our study concluded that attention to the removal, or at least mitigation, of pre-higher education barriers was important for facilitating entry into HEls for students with disabilities. Illustratively, instead of eliminating geometry and data-handling in math and science subjects in secondary school for blind and deaf students, inclusive education techniques must be employed, and accommodations provided within those courses (Lord, 2017, p. 20). Further, reforms in higher education can facilitate the removal of many barriers for students with disabilities in primary and secondary levels of education. Poignantly, teachers trained in inclusive education at HEls can develop and disseminate expertise on assistive technology, occupational therapy, and sign language at secondary school levels (Lord, 2017).

\subsection{Addressing Law/Policy and Data Gaps}

Egypt can bring about the implementation of international disability standards by strengthening its legal and regulatory framework in the light of the CRPD and by ratifying the Marrakesh Treaty. Policy development is also fundamentally important to inclusive higher education at both the national and university level given the autonomy exercised by many HEls in addressing disability inclusion (Lord, in press). There is a need for coherent university-wide policies on non-discriminatory enrolment and selection of academic courses, equal access to course material and curricula, the provision of reasonable accommodations, and grievance processes to address instances of discrimination-including failures to provide these supports (CRPD Committee, 2016, para. 63). Trenchantly, disability support services require specific policies, procedures, trainings, and authorization that apply specifically to all departments and teaching staff to enable their implementation (Lord, 2017, p. 20). Further, university-wide policies on making examinations accessible for students with disabilities can serve to eliminate discretionary decision-making by individual faculty members (Lord, 2017). Finally, uniform and expedient disability-inclusive HEI policies must extend to procurement policies, especially in relation to obtaining ICTs and equipment (e.g., software and computers) where the principle of user-testing should be reflected in policy (Haddon et al., 2005).

Measures must be undertaken at all levels of education regarding the participation of students with disabilities to address the persistent data gaps (Lord, 2017). Data on primary, secondary and higher education must capture and disaggregate on the basis of disability type, school enrolment, retention and advancement (CRPD Committee, 2016, para. 66). Gathering disability-specific data and statistics-admittedly challenging given the persistence of stigma and attendant reluctance to selfdisclose-is crucial for informing HEI policy and programming on accommodating students with disabilities (CRPD, 2006, art. 31).

\subsection{Tackling Disability Stigma}

HEls must address the causes of disability stigma and discrimination among faculty and staff, including misperceptions about disability accommodations conferring an unfair advantage (Riddell, 1999). Further, students with 
disabilities should be empowered to understand their rights and self-advocate, recognizing that cultural mores create internalized stigma and support the myth of accommodations being a "favour" rather than a required duty (Lord, 2017, p. 24).

To this end, HEls can use CRPD Article 8's awareness raising mandate to break down stigma and foment positive imagery (CRPD, 2006, art. 8). This could involve trainings for students, faculty, staff, and administrators, especially according to active learning principles that expose the fallacy of common stereotypes through dialogue between persons with disabilities and targeted participants. A practical element of enhancing such awareness is building knowledge about the duty of HEls to provide reasonable accommodations to facilitate equal access to academic programming, including exams and course materials (Lord, 2017, p. 21). A precondition to understanding the duty to provide reasonable accommodation is imparting the sense that accommodations are equalizing measures and do not convey extra-advantage. Specifically, that extra time for handwriting exam answers or being able to conduct an exam in Braille are measures for providing meeting student needs equal access. Further, that they do not undermine or compromise the assessment needs of the faculty member. HEls must likewise train faculty and staff on strategies for delivering content accessibly, or for modifications to provide better access to students, for example, allowing for students with hearing disabilities to sit up front, or describing images for students with visual disabilities (Lord, 2017, pp. 19-20).

\subsection{Advancing Disability Inclusive Curricula, Materials, and Examinations}

Inclusive education for students with disabilities requires access to course curricula, materials, and examinations and therefore requires their provision in accessible formats (CRPD, 2006, art. 24). Hence, HEls must put into place a system for the timely distribution of accessible formats of materials to students with disabilities to prevent delayed access that compromises quality inclusive education. Failure to consult with students about their specific needs and, crucially, their suggested solutions is likely to result in wasted resources. Ensuring equal access to examinations for students with disabilities suggests not only the need for clear policies on equal access to examinations, but specific guidance and clear directives on accessibility to faculty on good practice with illustrative accommodations for students with different disabilities. This should include training for faculty and $\mathrm{HEI}$ administration on the duty to make examinations accessible, and the provision of accommodations that do not fundamentally alter the nature of the academic program (CRPD, 2006, art. 24).

Academic curriculum must be inclusive if a wholeof-institution approach is to take hold in HEls. Disabilityinclusive curricula and research agendas within HEls can serve to incentivize the development of disability exper- tise within HEls. as suggested by research in South Africa (Ohajunwa, McKenzie, \& Lorenzo, 2015). Opportunities to develop disability-inclusive curricula can likewise help change attitudinal perceptions, and some of these approaches were beginning to emerge in some Egyptian HEIs (Lord, 2017, p. 13). Bringing these initiatives to scale and working to include in the curriculum courses on disability law, disability studies, inclusive education and accessibility in ICTs, among others, ought to be prioritized.

Finally, the value of disability-inclusive curricula is borne out by the emergence of disability studies as a discrete discipline within higher education in the United States, the United Kingdom, and elsewhere. Prioritisation could include developing disability studies in the humanities; sign language teaching and accreditation; inclusive education teacher training (e.g., including inclusive education training for new teachers, allowing students with disabilities entry into teacher training courses, and promoting university-sponsored workshops for training teachers); ICT accessibility (in relation to assistive technologies, e-learning accessibility, and accessible web content development) for specialized faculties (e.g., computer information, computer science); and disability law, and international and comparative disability law.

\subsection{Creating Barrier-Free Infrastructure}

Creating barrier-free infrastructure is fundamental to fostering an enabling environment for students, faculty, and staff with disabilities (Lord, 2017, p., 18). The two elements required are dismantling existing barriers in $\mathrm{HEI}$ infrastructure and ensuring that new building and infrastructure projects are made accessible to persons with disabilities. Consistent with the CRPD (and common sense) this must be conducted by government in consultation with persons with disabilities and their representative organizations. Such collaboration can develop guidelines and plan new infrastructure by efficaciously drawing on the knowledge and lived experiences of persons with disabilities in accessing their environments (CRPD, 2006, arts. 4, 9). Engagement with local disability rights groups can serve to: (1) identify, prioritize, and effectively plan for barrier removal; (2) effectively train $\mathrm{HEI}$ personnel responsible for infrastructure and accessibility; and (3) support innovative pilots utilizing HEI faculty and students, including students with disabilities, to integrate barrier removal into practical training and service learning under the aegis of relevant faculties, like engineering and architecture.

\subsection{Ensuring ICT Accessibility}

Training for HEl information and communications personnel on international standards and guidelines on web content accessibility and their application to HEls is a priority to remove persistent barriers in the online environment (Simpson, 2009). Further, practical training of faculty on accessibility practices for PDFs, PPTs, and other 
modes of content delivery in-class, and support for development and piloting of online courses in accessible formats is an imperative given the increasing reliance on such materials in HEls (Ziegler \& Sloan, 2017). Guidance provided by CRPD Article 9 and General Comment No. 2 on accessibility applies equally to information and communication technology, as it does for other elements of accessibility such as physical infrastructure (CRPD, 2006, art. 9; CRPD Committee, 2014).

\section{Conclusion}

The adoption of the CRPD in 2006 and its subsequent near universal ratification point to global recognition that the right to inclusive education for persons with disabilities at all levels of education is firmly embedded in human rights law. Currently this promise is unfulfilled at all levels of education worldwide, but progress is underway, spurred on by the CRPD's legal framework and its institutional arrangements. For countries like Egypt to make good on their legal commitments to inclusive education, international donors and their implementing partners must turn their attention to higher education. Ironically, but positively, the potential assets to advance inclusion in higher education and in primary and secondary education lie untapped within institutions of higher education yet close-by in local organizations of persons with disabilities.

\section{References}

Ainscow, M., \& Florek, A. (1989). A whole school approach. In M. Ainscow \& A. Florek (Eds.), Special educational needs: Towards a whole school approach (pp. 1-6). London: David Fulton Publishers.

CAPMAS. (2017). Central agency for public mobilization and statistics in Egypt: Results of 2017 census. Cairo: CAPMAS. Retrieved from sis.gov.eg/Story/ 9?lang=en-us

Committee on the Rights of Persons with Disabilities. (2014). General comment no. 2: Accessibility CRPD/C/GC/2. Retrieved from tbinternet.ohchr.org/ _layouts/treatybodyexternal/Download.aspx?symbol no=CRPD/C/GC/2\&Lang=en

Committee on the Rights of Persons with Disabilities. (2016). General comment no. 4: Right to inclusive education CRPD/C/GC/4. Retrieved from tbinternet. ohchr.org/_layouts/treatybodyexternal/Download. aspx? symbolno=CRPD/C/GC/4\&Lang=en

Constitution of Egypt. (2014). Constitution of Egypt. Cairo: Government of Egypt.

Convention on the Rights of the Child. (1989). Convention on the rights of the child: Adopted and opened for signature, ratification and accession by General Assembly 1577 U.N.T.S 3. Retrieved from www.ohchr. org/Documents/Professionallnterest/crc.pdf

Convention on the Rights of Persons with Disabilities. (2006). Convention on the rights of persons with disabilities No. 44910. Retrieved from treaties. un.org/Pages/ViewDetails.aspx?src=TREATY\&mtdsg_ no=IV-15\&chapter $=4 \&$ clang=_en

Danso, A. K., Owusu-Ansah, F. E., \& Alorwu, D. (2012). Designed to deter: Barriers to facilities at secondary schools in Ghana. African Journal of Disability, 1(1). Advanced online publication. http://dx.doi.org/ 10.4102/ajod.v1i1.2

de Beco, G. (2016). Transition to inclusive education systems according to the Convention on the rights of persons with disabilities. Nordic Journal of Human Rights, 34(1), 40-59.

Emong, P. (2014). The realisation of human rights for disabled people in higher education in Uganda: A critical analysis drawing on the UN Convention on the rights of persons with disabilities (Unpublished Doctoral Dissertation). University of Leeds, Leeds, UK.

Foundation of Tertiary Institutions of the Northern Metropolis. (2011). Disability in higher education project report for the Ford Foundation. New York, NY: Ford Foundation.

Haddon, L., Mante, E., Sapio, B., Kommonen, K. H., Fortunati, L., \& Kant, A. (Eds.). (2005). Everyday innovators: Researching the role of users in shaping ICTs. London: Springer.

Harpur, P., \& Stein, M. A. (in press-a). Children with disabilities, human rights, and sustainable development. In C. Fenton-Glynn (Ed.), Children's rights in international sustainable development law. Manuscript in preparation.

Harpur, P., \& Stein, M. A. (in press-b). Universities as disability rights change agents. New England University Law Review. Manuscript in preparation.

Heymann, J., Stein, M. A., \& Moreno, G. (2014). Disability, employment, and inclusion worldwide. In J. Heymann, M. A. Stein, \& G. Moreno (Eds.), Disability and equity at work (pp. 1-19). New York, NY: Oxford.

Leonard Cheshire Disability. (2017). Still left behind: Pathways to inclusive education for girls with disabilities. London: Leonard Cheshire. Retrieved from www.ungei.org/Still_Left_Behind_Full_Report.PDF

Linder, K. E., Fontaine-Rainen, D. L., \& Behling, K. (2015). Whose job is it? Key challenges and future directions for online accessibility in US institutions of higher education. Open Learning, 30(1), 21-34.

Lord, J. E. (2017). Needs assessment of persons with disabilities in Egyptian public universities and technical colleges. Final report and executive summary. Cairo: USAID.

Lord, J. E. (in press). Advancing the right to inclusive education in development cooperation. In G. de Beco, J. E. Lord, \& S. Quindlen (Eds.), The right to inclusive education in human rights law. London: Cambridge.

Marrakesh Treaty. (2013). Marrakesh treaty to facilitate access to published works for persons who are blind, visually impaired, or otherwise print disabled. Marrakesh. Retrieved from www.wipo.int/wipolex/ en/treaties/text.jsp?file_id=301019 
Miller, P., Parker, S., \& Gillinson, S. (2004). Disablism: How to tackle the last prejudice. London: Demos.

Ohajunwa, C., McKenzie, J., \& Lorenzo, T. (2015). Enabling disability inclusive practices within the University of Cape Town curriculum: A case study. African Journal of Disability, 4(1). Advanced online publication. Retrieved from ajod.org/index.php/ajod/ article/view/157/339

OECD. (2003). Transforming disability into ability. OecdIlibrary. Retrieved from read.oecd-ilibrary.org/socialissues-migration-health/transforming-disability-intoability_9789264158245-en\#page1

Persons with Disabilities Act 2018. Cairo: Government of Egypt.

Reiser, R. (2012). Implementing inclusive education: A commonwealth guide to implementing article 24 of the Un Convention on the rights of persons with disabilities. London: Commonwealth Secretariat.

Riddell, S. (1999). Chipping away at the mountain: Disabled students' experiences of higher education in South Africa. International Studies of Sociology and Education, 8, 203-222.

Reiko, H., \& May, G. E. (2011). The effect of exposure to a professor with a visible disability on students' attitudes toward disabilities. Journal of Social Work in Disability \& Rehab, 10(1), 36-48.

SCU Decree. (2016). Supreme Council of universities decree. Cairo: Government of Egypt.

Shildrick, M. (2012). Critical disability studies: Rethinking the conventions for the age of postmodernity. In N. Watson, A. Roulstone, \& C. Thomas (Eds.), Routledge handbook of disability studies (pp. 30-41). London: Routledge.

Simpson, J. (2009). Inclusive information and communication technologies for people with disabilities. Disability Studies Quarterly, 29(1). Advanced online publication. Retrieved from www.dsq-sds. org/article/view/167/167

Standard Rules. (1993). On the equalization of opportunities for persons with disabilities UN Doc. A/48/49. Retrieved from hrlibrary.umn.edu/resolutions/48/
96GA1993.html

Trani, J. F., Kett, M., Bakhshi, P., \& Bailey, N. (2011). Disability, vulnerability and citizenship: To what extent is education a protective mechanism for children with disabilities in countries affected by conflict? International Journal of Inclusive Education, 15(10), 1187-1203.

UN Development Programme. (2016). Egypt: Sustainable development goals (SDGs). Cairo: UNDP. Retrieved from www.eg.undp.org/content/egypt/en/ home/sdgoverview/post-2015-development-agenda. html

UNESCO. (1994). The Salamanca statement and framework for action on special needs education. Paris: UNESCO. Retrieved from www.unesco.org/ education/pdf/SALAMA_E.PDF

UNESCWA. (2015). Disability in the Arab region: An overview. Beirut: United Nations Economic and Social Commission for Western Asia.

US Agency of International Development. (2017). Needs assessment of persons with disabilities in Egyptian public universities and regional technical colleges ( $\mathrm{Fi}$ nal Report). Washington, DC: USAID. Retrieved from https://pdf.usaid.gov/pdf_docs/PAOOSVGS.pdf

Von Hippel, E. (2005). Democratizing innovation. Cambridge, MA: MIT Press.

World Bank Group. (2007). Understanding the inclusivity of inclusive education, disability-inclusive knowledgesilo breaker knowledge brief (Washington, DC).

World Health Organization. (2015). Egypt health profile 2015 (Regional Office for the Eastern Mediterranean Report, WHO-EM/HST/225/E). Beirut: WHO.

World Health Organization \& World Bank Group. (2011). World report on disability. Washington, DC: WHO \& World Bank Group. Retrieved from www. who.int/disabilities/world_report/2011/report.pdf

Ziegler, M. J., \& Sloan, D. (2017). Accessibility and online learning. In J. Lazar \& M. A. Stein (Eds.), Disability, human rights, and information technology ( $\mathrm{pp}$. 158-168). Philadelphia, PA: University of Pennsylvania Press.

\section{About the Authors}

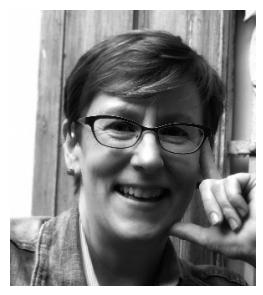

Janet E. Lord is an International Lawyer and Inclusive Development practitioner with more than 15 years of experience assessing, evaluating and monitoring development projects. She served as Team Leader for the QED Group resulting in USAID's first assessment on the accessibility of Egyptian universities to students with disabilities. A senior fellow at the Harvard Law School Project on Disability, she holds Law degrees from the George Washington University Law School (LLM) and the University of Edinburgh in Scotland (LLB \& LLM).

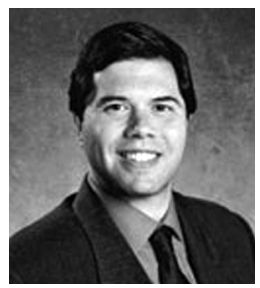

Michael Ashley Stein is Visiting Professor of Law at the Harvard Law School and Executive Director of the Harvard Law School Project on Disability. He holds an Extraordinary Professorship at the University of Pretoria Faculty of Law, Centre for Human Rights and regularly consults with governments and disabled people organizations on disability law and policy. A leading scholar on the human rights of persons with disabilities, he holds degrees from the Harvard Law School (JD), Cambridge University (PhD) and New York University (BA). 